\title{
Fractal Dimensions of Metropolitan AreaRoad Networks and the Impacts on the Urban Built Environment
}

\author{
Zhongming Lu ${ }^{\mathrm{a} *}$, Hong Zhang ${ }^{\mathrm{b}}$, Frank Southworth ${ }^{\mathrm{c}}$, John Crittenden ${ }^{\mathrm{a}}$ \\ ${ }^{a}$ Brook Byers Institute for Sustainable Systems, School of Civil and Environmental Engineering, Georgia \\ Institute of Technology, Atlanta, Georgia 30332, United States \\ ${ }^{\mathrm{b}}$ Faculty of Geosciences \& Environmental Engineering, Southwest Jiaotong University, Chengdu, Sichuan, \\ China \\ ${ }^{\mathrm{c}}$ School of Civil and Environmental Engineering, Georgia Institute of Technology, Atlanta, Georgia 30332, \\ United States
}

\section{Corresponding author*}

Zhongming $\mathrm{Lu}$

Address: Brook Byers Institute for Sustainable Systems, School of Civil and Environmental Engineering, Georgia Institute of Technology, Atlanta, Georgia 30332, United States

Phone: 01-404-791-0916

Email: zhongming.lu@gatech.edu

\section{Acknowledgements}

Financial support from the National Science Foundation throughgrants (\#0836046 and \# 1441208), is gratefully acknowledged. This work was also partially supported by Brook Byers Institute for Sustainable Systems, the Hightower Chair and Georgia Research Alliance. The authors would like to thank Dr. Doug Noonan, Dr. Xuewei Yu and the three anonymous reviewers for the comments and suggestions. The views and ideas expressed herein are solely of the authors and do not represent the ideas of the funding agencies in any form.

(C) 2016. This manuscript version is made available under the Elsevier user license http://www.elsevier.com/open-access/userlicense/1.0/ 


\section{Abstract}

2 The fractal dimension of road networksemerges as a measure of the complexity of road transport

3 infrastructures.In this study, we measured fractal dimensions of both the geometric form (i.e., the layout of

4 the roads) and structure hierarchy (i.e., the connections among roads) of the major road networks in the

5 largest 95 U.S. metro areas. We explained the causes of the variances in these fractal dimensions,

6 especially the one for structure hierarchy. Further, we hypothesized the impacts of these fractal dimensions

7 on the urban built environment and validated our hypotheses using path analysis. We found that a larger

8 geometric fractal dimension $\left(\mathrm{D}_{\mathrm{g}}\right)$ shows a more uniform distribution of roads over the metro area, which

9 provides the accessibility to suburban areas and incentives to low-density development. A larger structural

10 fractal dimension $\left(\mathrm{D}_{\mathrm{s}}\right)$ indicates the highly-connected roads (e.g., highways) tend to join to other highly-

11 connected roads so that most roads can be reached by a small number of neighboring roads (i.e., the small-

12 world phenomenon).As $\mathrm{D}_{\mathrm{s}}$ increasesand the small-world effect become more significant, daily vehicle miles

13 traveled per capita (DVMT/Cap) decline. However, $\mathrm{D}_{\mathrm{s}}$ should be kept low in order to reduce theDVMT/Cap

14 as population size increases. We consider that the low $\mathrm{D}_{\mathrm{s}}$ can contribute to more mixed, polycentric and

15 more uniform on an urban area-wide basis. Overall,higher $\mathrm{D}_{\mathrm{g}}$ and $\mathrm{D}_{\mathrm{s}}$ of the major road network in a metro

16 area leads to higher per capita carbon emissions of transport, andlower quality of lifeas population

17 increases.In the end, we conclude that fractal dimensions can provide valuable insight into the nature of the

18 transportation land use nexus.

\section{Keywords}

20 Road Network, Fractal Analysis, Path Analysis, Sustainable Urban Development, Carbon Footprint 


\section{Introduction}

Recent literature has shown thatthe road transport system is a fractal object, whose form and

23 structure isboth essentially irregular, scale invariant and self-similar(Kalapala et al., 2006; Lu and Tang,

24 2004; Zhang and Li, 2012).Fig. 1 displays the geometric topology and structural architecture of the metro

25 Atlanta road network includingfreeways, arterials, and collectors. In Fig. $1 \mathrm{~b}$ of the structural architecture,

26 nodes represent the roads and the links between nodes means the corresponding roads are connected. A

27 fractal dimension Dis an index for characterizing fractal patterns by measuring the change in detail in response to the change in geographic scales(Mandelbrot, 1983). There are two types of D measures that

29 have been developed for road networks. One is geometric $\mathrm{D}\left(\mathrm{D}_{\mathrm{g}}\right)$, which can distinguish how more or less uniformly road infrastructure is distributed in 2-dimensional space(Thomas and Frankhauser, 2013). The other measure is structural $D\left(D_{s}\right)$, which was first computed by Zhang et al to determine the fractal architecture of road networksin terms ofhow roads are connected with each other over a range of scales(Zhang and Li, 2012).

34

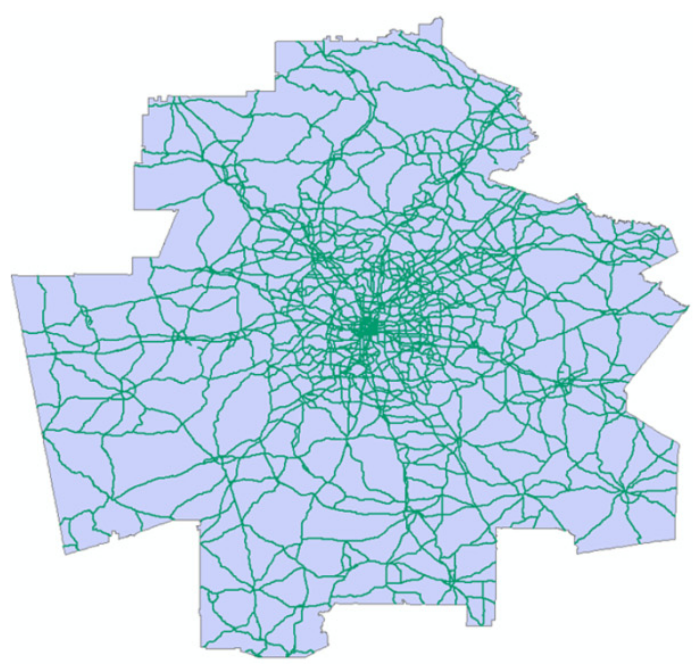

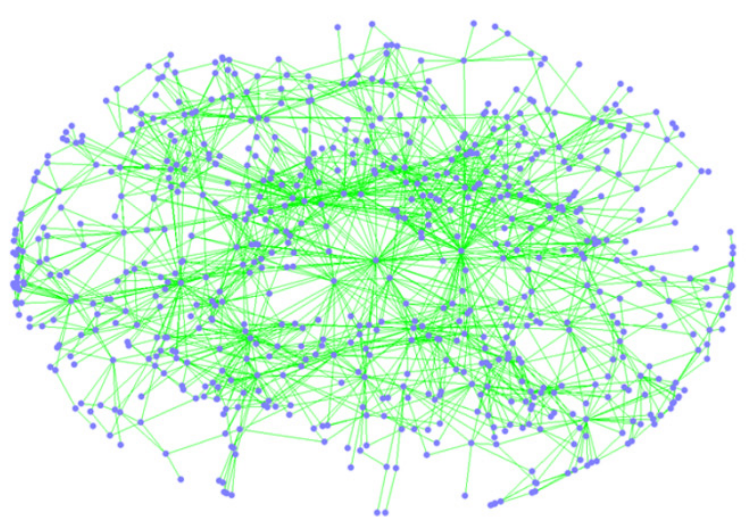

35

Fig.1. Geometrical and structural representation of road network in the metro Atlanta: (a) geometrical form;(b) structural representation (i.e., connectivity).

The $D_{g}$ and $D_{s}$ provides an overall measure for the complexity of the road network. The value of $\mathrm{D}_{\mathrm{g}}$ is a measure of the space filling capacity of road networks in the two-dimensional space(Batty and Xie, 1996). If the space filling capability is high, the road network tends to occupy the space more uniformly within a given boundary in the two-dimensional space (Thomas and Frankhauser, 2013). Accordingly, the 
$41 \mathrm{D}_{\mathrm{g}}$ of the road network can be large with an upper limit of two-dimensional(Chen, 2012). Instead, when the

42 space filling capability is low, the distribution of the road network becomes less uniform and the $\mathrm{D}_{\mathrm{g}}$ of the

43 road network is small with a lower limit of one. A set of models including diffusion-limited aggregation

44 (DLA) and dielectric breakdown model (DBM) have been developed to explain the difference in $\mathrm{D}_{\mathrm{g}}$ caused

45 by the space filling capacity(Meakin, 1983; Niemeyer et al., 1984). In terms of the fractal architecture of

46 networks, Song et al. proposed a mechanism for the growth of fractal complex networks (e.g., metabolic

47 network of Escherichia coli) (Song et al., 2006). Built upon the findings from Song et al., we will explain

48 the variance of $D_{s}$ caused by the difference in the mechanism of how we assemble the road network.

49 The usefulness of $\mathrm{D}_{\mathrm{g}}$ and $\mathrm{D}_{\mathrm{s}}$ in planning more sustainable road networks and cities depends on the

50 connections between the two fractal dimensions of road networks and the urban built environment. The

51 exploration between fractal dimensions of the road system and urban growth started in 90s, encouraged by

52 Batty and Longley(Batty and Longley, 1994). Thomas and Frankhauser explained the meaning of fractal

53 dimension for built-up areas and the geometrical form of road networks (Thomas and Frankhauser, 2013).

54 The lower ratio of fractal dimensions between built-up areas and the geometrical form of road networks in

55 a certain area indicates where roads are available but the land remains underdeveloped. Abundo et

56 al.investigated how urban population density and growth influences and is influenced by road network

57 infrastructure(Abundo et al., 2013). Results show that cities on more developed continents tend to

58 exhibithigher $\mathrm{D}_{\mathrm{g}}$ road networks. This implies that road network infrastructures in more developed cities

59 branches over more orders of magnitude than that in less developed cities. In addition, before the

60 development of $D_{s}$ of the road network, most studies only investigated the relationship between $D_{g}$ and

61 urban form (Lu and Tang, 2004; Thomas and Frankhauser, 2013). We will explicitly explain the linkages

62 between $\mathrm{D}_{\mathrm{s}}$ and the urban built environment.

63 In this study, we first made the hypotheses of the impacts of $\mathrm{D}_{\mathrm{g}}$ and $\mathrm{D}_{\mathrm{s}}$ on the urban built

64 environment and employed path analysis to validate these hypotheses. The path analysis is a useful

65 statistical technique for testing and estimating potentially causal relations(Etminani-Ghasrodashti and

66 Ardeshiri, 2015; Ewing et al., 2014;Nasri and Zhang, 2014).The path analysis allows us to explore the

67 direct and indirect paths between fractal dimensions and the urban built environment.Due to data sparsity,

68 the measures of the urban built environment in this study include urban population density(UPD), per 
capita daily vehicle miles traveled (DVMT/Cap), annual per capita carbon emissions of transport

70 (TCE/Cap/year), and the quality of life (QoL). We consider that lower TEC/Cap/year and higher QoL are

71 more sustainable. If the effects of $\mathrm{D}_{\mathrm{g}}$ and $\mathrm{D}_{\mathrm{s}}$ on the urban built environment are statistically significant, we

72 might offer another perspective from $D_{g}$ and $D_{s}$ to redesign road infrastructures and improve the urban built

73 environment.

74 The paper is organized as follows: Section 2 is a brief summary of the theories to interpret $D_{g}$ and

$75 D_{s}$, hypotheses of the impacts of $D_{g}$, and $D_{s}$ on the urban built environment; Section 3describes the data and

76 methods for calculating the $\mathrm{D}_{\mathrm{g}}$ and $\mathrm{D}_{\mathrm{s}}$ of roadnetworks and the construction of path analysis; Section 4

77 represents the results of $\mathrm{D}_{\mathrm{g}}, \mathrm{D}_{\mathrm{s}}$ and path analysis; Section 5 and 6 is discussion and conclusion, respectively.

\section{2. Theories and Hypotheses}

\section{2.1. The Theory to Explain the Change in $D_{g}$ Value of Road Networks}

There are multiple mathematical models including DLA and DBM to understand the process that

81 leads to the emergence of geometrical fractal patterns. The DLA describes the process how particles

82 undergoing a random walk cluster together to form aggregates of particles. The DBM is a stochastic model

83 to simulate dielectric breakdown. Considering the similarity between road expansion and the branching of

84 discharge channels, the DBM is more suitable to understand the space filling capability. In the DBM, the

85 space filling capability is defined as the dependence on local electric field. The low dependence means a

86 high space filling capability of the electrons. If the dependence is low, then the discharge tends to

87 breakdown the area more uniformly. As a result, the $\mathrm{D}_{\mathrm{g}}$ of the branches tends to be large. Instead, if the

88 dependence is high, the distribution of branches is less uniform and the $\mathrm{D}_{\mathrm{g}}$ tends to be small. We can borrow

89 the same underlying factor of dielectric breakdown to understand the geometric form of road infrastructure

90 systems. The space filling capability of road infrastructures implies some dependences on local conditions,

91 which might be caused by land use constraints, policies and economic development.

92 2.2. Hypotheses of the Impacts of $D_{g}$ on the Urban Built Environment

93 A larger $\mathrm{D}_{\mathrm{g}}$ represents a more uniformly distributed network.Because of the increasing supply of

94 roads which provides accessibility to suburban areas and incentives to low-density development, we

95 hypothesize that the UPD will decline as $\mathrm{D}_{\mathrm{g}}$ increases. However, the negative impact of $\mathrm{D}_{\mathrm{g}}$ on UPD can be

96 mitigated as population increase and fill up the metro area. Meanwhile, although the supply of road 
97 infrastructures in the suburban areas increases in the case of a large $\mathrm{D}_{\mathrm{g}}$, housing and population density

98 may not reach the same level as it does in more central urban areas and therefore the incentive for suburban

99 shopping, foods, and other recreational facilities remains comparatively low. Accordingly, the quality of

100 life in the metro area may be low.

101 2.3. The Theory to Explain the Change in $D_{s}$ value of Road Networks

102 Song et al. proposed a mechanism for the growth of fractal complex networks (e.g., metabolic

103 network of Escherichia coli) (Song et al., 2006). If the highly connected nodes are directly connected with

104 other high degree nodes to formalize a complex large network (Type I), a small-world network emerges

105 (the emergence of a great hub as shown in Fig. 2a) but without fractal topology. Conversely, if the highly

106 connected nodes are connected indirectly through the connection with low degree nodes (Type II), then a

107 network with fractal topology but not the small-world effect does appear (Fig. 2b). If the highly connected

108 nodes are attached to either high degree nodes directly (Type I) or indirectly through low degree nodes

109 (Type II) with a certain probability to formalize a complex large network, the network has both small-world

110 effect and fractal topology (Fig.2c).Based on the above mechanisms to develop a large network, the fractal

111 dimension of the network increases if the probability $p$ declines for linking highly connected nodes

112 connected to low connected degree nodes (Type II). When $\mathrm{p}=0$, the network is non-fractal.That is, the

113 high fractal dimension network has more significant small-world properties than networks with a low

114 fractal dimension. 
(a)

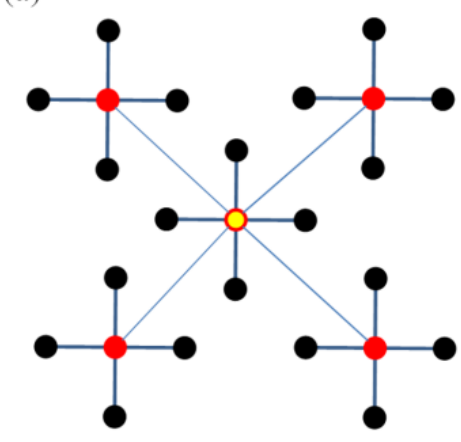

(b)

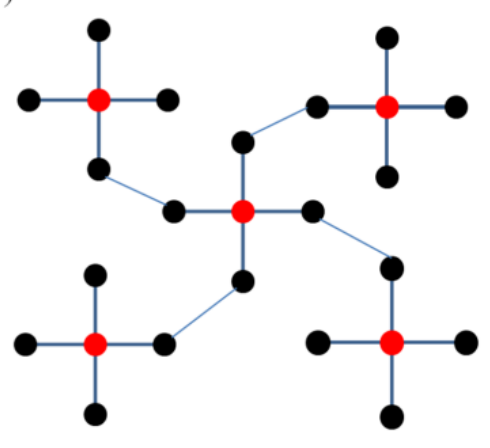

(c)
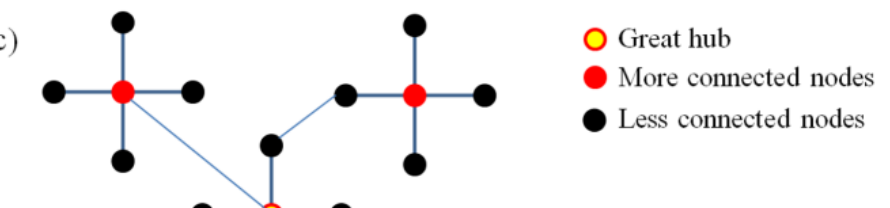

116 Fig.2. Mechanisms of forming a small-world network and a fractal-like network: a) direct connections

117 between higher degree nodes lead to the small-world effect without fractal topology (Type I); b) indirect connections between higher degree nodes lead to a fractal topology but without small-world effect (Type II); c) the network has both small-world effect and fractal property with the combination of Type I and Type II with probability $p=0.5$.

\subsection{Hypotheses of the Impacts of $D_{s}$ on the Urban Built Environment}

Based on the interpretation of $\mathrm{D}_{\mathrm{s}}$ and the connectivity of road network, we made two hypotheses

123 for the effect of $\mathrm{D}_{\mathrm{s}}$ on DVMT/Cap. On the one hand, given the characteristic of small-world effect, DVMT/Cap will decline as $\mathrm{D}_{\mathrm{s}}$ increases because of the existence of highly connected roads(e.g., high volume freeways) that have a larger number of connections with more roads. This advantage of smallworld networks is consistent with a previous study by Latora and Marchiori that proved that the smallworld network is an efficient form of transportation (Latora and Marchiori, 2001).On the other hand, as the road network relies more on a few high volume freeways for transporting, most roads become less important as $\mathrm{D}_{\mathrm{s}}$ increases. These roads only provide incentives to low-density development as population increases. High density and commercial development occurs more likely around the intersections of highways. Instead, when $\mathrm{D}_{\mathrm{s}}$ is smaller and more low degree roads (e.g., arterials and collectors) plays 
132 important roles of connecting highways, more land along these low-degree roads become valuable for high 133 density and commercial development. These low-degree roads are not directly connected with each other

134 and correspondingly incentivize the development of multiple commercial centers as population increases.

135 The decentralization of commercial centers will lead to a reduction in DVMT/Cap. Overall, the first

136 hypothesis is made based on the efficiency of small-world network itself in transporting. The second

137 hypothesis is made based on the dynamics of land use and transportation nexus. $\mathrm{D}_{\mathrm{s}}$ have both positive and

138 negative impacts on DVMT/Cap and the net impact depends on population size.

\section{3. Data and Methodologies}

140 3.1. Data

141 We collected road network, population, urban area, economic development, and traffic data (i.e.,

142 lines of lanes, daily vehicle miles traveled, and transportation carbon emissions) for the 95 U.S.

143 metropolitan areas. Road networks are required for calculating $D_{g}$ and $D_{s}$. The data of road networks was

144 available for year 2005 from the ArcGIS resources

145 (http://resources.arcgis.com/en/help/main/10.1/index.html\#//001z00000039000000). The road network

146 composed of freeways, arterials, and collectors. We did not include local streets in the network analysis

147 because current algorithms is inefficient to consider local streetsfor calculating the $\mathrm{D}_{\mathrm{s}}$. To build the path

148 model, the 2010 metro population, gross metropolitan products, urban population and areas were obtained

149 from U.S. Census. We chose the 2011 traffic data available from 2012 Urban Mobility Report given the

150 fact that total transport carbon emissions are not available in previous Urban Mobility reports (Schrank et

151 al., 2012). QoL is measured in this research by the Well-Being Index from Gallup. The index measures

152 Americans' perceptions of their lives and their daily experiences of life evaluation, emotional health,

153 physical health, healthy behavior, work environment and basic access (Gallup and Healthways, 2013).The

154 Well-Being index is calculated on a scale of 0 to 100 , which zero represents the lowest possible well-being

155 and 100 represents the highest possible well-being. The summary of variables in the path model is provided

156 in Table 1. In this study, we explored the longer term impacts of $D_{g}$ and $D_{s}$ in 2005 on the urban built

157 environment after 6 years. We consider that there are delayed responses to the properties of road networks.

158 For example, real estate developers need years to build new homes and offices regarding to the investment 
or upgrading of road networks. In general, it takes about five to six years before the structural change of the urban built environment can be felt(Cervero, 2003; Nasri and Zhang, 2014).

161 Table 1. Variables included in the path model.

\begin{tabular}{|l|l|c|c|}
\hline Variables description & Data source & Mean & Standard deviation \\
\hline Natural log of urban population & US census & 13.85 & 0.94 \\
\hline Natural log of UPD & $\begin{array}{l}\text { US census, Urban } \\
\text { mobility report }\end{array}$ & 7.80 & 0.36 \\
\hline $\begin{array}{l}\text { Ratio of urban population to metro } \\
\text { population }\end{array}$ & US census & 0.77 & 0.13 \\
\hline $\begin{array}{l}\text { Natural log of urban lane density } \\
\text { (mile/square mile) }\end{array}$ & Urban mobility report & 1.87 & 0.33 \\
\hline $\begin{array}{l}\text { Natural log of DVMT/Cap } \\
\text { (miles/day/person) }\end{array}$ & Urban mobility report & 2.93 & 0.21 \\
\hline $\begin{array}{l}\text { Ratio of auto commuters to urban } \\
\text { population }\end{array}$ & $\begin{array}{l}\text { US census, Urban } \\
\text { mobility report }\end{array}$ & 0.54 & 0.07 \\
\hline $\begin{array}{l}\text { Natural log of TCE/cap/year (pounds } \\
\text { CO2/year/person) }\end{array}$ & Urban mobility report & 8.87 & 0.24 \\
\hline $\begin{array}{l}\text { Natural log of per capita gross } \\
\text { metropolitan products (\$/person/year) }\end{array}$ & US census & 11.05 & 0.31 \\
\hline QoL: quality of life & Gallup & 67.15 & 1.68 \\
\hline
\end{tabular}

\subsection{Overview of the Analysis Steps and Methods}

The analysis started with the measure of geometric fractal dimension $\left(\mathrm{D}_{\mathrm{g}}\right)$ using box-counting algorithm. To calculate the structural fractal dimension $\left(D_{\mathrm{s}}\right)$, we first converted the geometric form of road network to its structural form. We used the Maximum Excluded Mass Burning (MEMB) algorithm developed by Song et al. to compute the $\mathrm{D}_{\mathrm{s}}$ of the road network (Song et al., 2006). We also measured the small-world property and network connectivity of the structural networks to verify the mechanism for the

170 and $\mathrm{D}_{\mathrm{s}}$ with the urban built environment.

\section{$171 \quad$ 3.2.1. Box-Counting Algorithm for Computation of Geometric Fractal Dimension $\left(D_{g}\right)$}

172 Box counting is a method of measuring fractal dimension of geometric objects. We used a Matlab

173 box counting algorithm to compute the geometric fractal dimension $\mathrm{D}_{\mathrm{g}}$ of road network (Moisy, 2008). We

174 begin by rendering the metro data image to a $1790 \times 2522$ logical array (i.e., it contains only 0 and 1 ). The

175 algorithm overlaid the grids with the box of size $R$ to cover the image. The box sizes are power of two, i.e.,

$176 R=1,2,4 \ldots 4096$. For each sized grid, we counted the number of boxes $N$ with a road in it. If the object is

177 a fractal, then it will follow a power-law $\mathrm{N}=\mathrm{c}^{*} \mathrm{R}^{\wedge}\left(-\mathrm{D}_{\mathrm{g}}\right)$, where $\mathrm{c}$ is constant and $\mathrm{D}_{\mathrm{g}}$ less than 2.

\section{3.2.2. Conversion of Road Network from Geometric Form to Structural Representation}


In the geometric form of road network, each road segment is connected with two or more road segments. We first connect two neighboring road segments to form a long natural road within the threshold of $60^{\circ}$ deflection angle (Zhang and $\mathrm{Li}, 2012$ ). The formation of natural roads is based on the Gestalt principle of good continuity, which states that from a human perceptive the segments that continue on a visual line should be grouped together. The process goes on until the deflection angle is greater than 60 degrees and is repeated until all road segments are visited. The process is an approximation of how a road network is self-organized to form a complex transport hierarchy. Further, we used the roads as nodes and the connections as the links to represent the structural topology of the road network. This abstract representation demonstrates a structure of how roads are connected with each other.

\subsubsection{MEMB for Computation of Structural Fractal Dimension $\left(D_{s}\right)$}

The MEMB algorithm follows the same philosophy of the box-counting approach. For each box of size $l$, we need to count the minimum number of boxes $\left(N_{s}\right)$ that covers all the nodes in the graph. The box size is defined as the number of steps between two nodes and therefore, the maximum distance between two nodes cannot exceed to the size of the box. If the graph is a fractal, then we would observe a power-law $\mathrm{N}_{\mathrm{s}}=\mathrm{c}^{*} l^{\wedge}\left(-\mathrm{D}_{\mathrm{s}}\right)$, where $\mathrm{c}$ is constant. More details of the algorithm can be referred to the previous research

194 (Song et al., 2006).

\section{3.2.4. Verification of the Mechanism for the Growth ofthe Fractal Structure}

We verified the theory to explain the variance in $\mathrm{D}_{\mathrm{s}}$ based on the 95 structural networks of real

197 road infrastructures. We measured the small-world property of the road structural network using clustering 198 coefficient (CC) (Eqs. 1 and 2). However, we cannot directly compare the CCs of two road structural networks because of the difference in number of nodes and some unknown random effects. Therefore, we

200 randomly rewired $20 \%$ of the links in the original road structural network and accordingly the small-world 201 effect is reduced by breaking links between most-connected nodes (Kitsak et al., 2007). The loss should be more significant for the road structural network with larger structural fractal dimension $\left(D_{\mathrm{s}}\right)$ (Zhang and Li, 203 2012).

$$
C_{i}=\frac{2\left\{e_{p g}\right\}}{k_{i}\left(k_{i}-1\right)}
$$


where, $k_{i}$ is the number of neighbors (p, q ...) of node $\mathrm{i} ; e_{p g}$ is the number of links among neighbor

$207 \mathrm{p}, \mathrm{q}$ of node $\mathrm{i} ; \mathrm{n}$ is the number of nodes.

We also measured network connectivity using average betweenness of the roads (i.e., ratio of the number of shortest paths between any two nodes that passing the node of interest to the number of shortest path between any two nodes other than the node of interest; see Eqs. 3-5).The road network with a small

$$
B_{i}=\sum_{i \neq j \neq k} \frac{N_{j k}(i)}{N_{j k}}
$$

15

$$
\operatorname{Normal}\left(B_{i}\right)=\frac{B_{i}-\min (B)}{\max (B)-\min (B)}
$$

where, $N_{j k}$ is the number of shortest paths from node $\mathrm{j}$ to node $\mathrm{k} ; N_{j k}(i)$ is the number of those

218 paths that pass through $\mathrm{i} ; N$ is total number of nodes.

\section{3.2.5. Path Development and Statistical Analysis}

The path analysis is an extension of multiple regression analysis to test and verify the multilevel

221 cause-effect relationships. It allows for the complex interdependency among variables to approximate the

222 interactions in a complex system. As compared to single regression analysis, the path analysis allows the

223 partition of net effects into direct and indirect associations. The path analysis was firstly used by

224 psychologists and later it becomes a popular tool used by ecologists to study the dynamics of ecosystems.

225 However, the application of path analysis to study the interactions between transportation and the built

226 environmentis limited, mainly focusing on the study of travel behaviors. Nasri and Zhang developed a path

227 model to study the relationship between macro-level urban form, regional mobility and travel behaviors

228 (Nasri and Zhang, 2014). The analysis suggests that the overall form of urban areas plays a more important 
229 role than the pattern at neighborhood scale in influencing the travel demand. Ewing et al. developed a path 230 model to quantify the elasticity values of vehicle miles traveled with respect to different urban variables in 231 US urbanized areas (Ewing et al., 2014).

232 We built and refined a theoretical model which reflects the interrelationships amongfractal 233 dimensions, land use, traffic, and other socio-economic factors (Table 2). The connections among variables 234 other than those related to $D_{g}$ and $D_{s}$ have been discussed or verified(Cervero and Murakami, 2010; Lin and 235 Yang, 2009; Nasri and Zhang, 2014;Silva et al., 2012). Adding these variables can help explore the impacts 236 of $D_{g}$ and $D_{s}$ on transportation and land use. But it should be noted that our path model only captured a 237 handful of factors that influence the urban built environment and our goal of the path analysis is to test the 238 hypotheses for the impacts of $\mathrm{D}_{\mathrm{g}}$ and $\mathrm{D}_{\mathrm{s}}$. On a methodological note, we used the observationsof 95

239 metropolitan areas to run our path analysis. The total sample size is not large but we guaranteed more than

240 five observations per parameter (i.e., path coefficients and error terms) (Bentler and Chou,

241 1987).Meanwhile, we did notmiss any path that is statistically significant (have non-zero values).The final

242 path model best captured the interrelationships of the variables we had in this study to explore impacts of

$243 \mathrm{D}_{\mathrm{g}}$ and $\mathrm{D}_{\mathrm{s}}$ on transportation and land use.

244 We used the STATA 13 software and robust maximum likelihoodto avoid the assumption of

245 multivariate normality of endogenous variables (which is equivalent to the dependent variable in linear

246 regression). The standardized root mean squared residual is 0.04 , which is smaller than recommended 0.08

247 (Hu and Bentler, 1999). The estimated total effects of UPD, density of roadway lane miles and per capita

248 gross metropolitan product on DVMT/Cap is in the line with previous studies which have quantified the

249 influence of built environment on vehicle miles traveled (Cervero and Murakami, 2010). The relationships

250 in the path analysis are statistically significant and as such are amenable to test the relationships between

251 fractal dimensions of road networks and the urban built environment.

252 Table 2. The paths and hypotheses included in path analysis.

\begin{tabular}{|l|l|l|l|}
\hline Path & End & Hypotheses & Reference \\
\hline Start & Natural log of UPD & UPD will decline as $\mathrm{D}_{\mathrm{g}}$ increases. & This study \\
\hline $\mathrm{D}_{\mathrm{g}}$ & Natural log of UPD & $\begin{array}{l}\text { The negative impacts of } \mathrm{D}_{\mathrm{g}} \text { on UPD } \\
\text { can be mitigated as urban population } \\
\text { increases. }\end{array}$ & This study \\
\cline { 1 - 1 } $\begin{array}{l}\mathrm{D}_{\mathrm{g}} * \text { natural log of } \\
\text { urban population }\end{array}$ & Natural log of UPD & $\begin{array}{l}\text { UPD will increase as urban lane density } \\
\text { increases. }\end{array}$ & $\begin{array}{l}\text { (Wade et al., } \\
1999)\end{array}$ \\
\hline $\begin{array}{l}\text { Natural log of urban } \\
\text { lane density }\end{array}$ & \multicolumn{2}{|l|}{} \\
\hline
\end{tabular}




\begin{tabular}{|c|c|c|c|}
\hline $\begin{array}{l}\text { Ratio of urban } \\
\text { population to the } \\
\text { metro population }\end{array}$ & $\begin{array}{l}\text { Natural log of } \\
\text { DVMT/Cap }\end{array}$ & $\begin{array}{l}\text { More urban population will contribute } \\
\text { to a lower DVMT/Cap. }\end{array}$ & $\begin{array}{l}\text { (U.S Department } \\
\text { of Transportation, } \\
\text { 2009) }\end{array}$ \\
\hline $\mathrm{D}_{\mathrm{s}}$ & $\begin{array}{l}\text { Natural log of } \\
\text { DVMT/Cap }\end{array}$ & $\begin{array}{l}\text { DVMT/Cap will decline as } \mathrm{D}_{\mathrm{s}} \\
\text { increases. }\end{array}$ & This study \\
\hline $\begin{array}{l}D_{s} * \text { natural } \log \text { of } \\
\text { urban population }\end{array}$ & $\begin{array}{l}\text { Natural log of } \\
\text { DVMT/Cap }\end{array}$ & $\begin{array}{l}\text { The growth of urban population will } \\
\text { offset the positive impacts of } D_{s} \text { on } \\
\text { reducing DVMT/Cap. }\end{array}$ & This study \\
\hline $\begin{array}{l}\text { Natural log of urban } \\
\text { lane density }\end{array}$ & $\begin{array}{l}\text { Natural log of } \\
\text { DVMT/Cap }\end{array}$ & $\begin{array}{l}\text { The growth of urban lane density will } \\
\text { increase DVMT/Cap. }\end{array}$ & $\begin{array}{l}\text { (Ewing et al., } \\
\text { 2014) }\end{array}$ \\
\hline $\begin{array}{l}\text { Natural log of per } \\
\text { capita gross } \\
\text { metropolitan } \\
\text { products }\end{array}$ & $\begin{array}{l}\text { Natural log of } \\
\text { DVMT/Cap }\end{array}$ & $\begin{array}{l}\text { Higher per capita gross metropolitan } \\
\text { products will contribute to higher } \\
\text { DVMT/Cap. }\end{array}$ & $\begin{array}{l}\text { Cervero and } \\
\text { Murakami, 2010; } \\
\text { Ewing et al., } \\
\text { 2014) } \\
\end{array}$ \\
\hline Natural log of UPD & $\begin{array}{l}\text { Natural log of } \\
\text { DVMT/Cap }\end{array}$ & $\begin{array}{l}\text { Higher UPD will contribute to lower } \\
\text { DVMT/Cap. }\end{array}$ & $\begin{array}{l}\text { (Cervero and } \\
\text { Murakami, 2010; } \\
\text { Ewing et al., } \\
\text { 2014) } \\
\end{array}$ \\
\hline $\begin{array}{l}\text { Natural log of } \\
\text { DVMT/Cap }\end{array}$ & $\begin{array}{l}\text { Natural log of } \\
\text { TCE/Cap/year }\end{array}$ & $\begin{array}{l}\text { Higher DVMT/Cap will contribute to } \\
\text { higher TCE/Cap/year. }\end{array}$ & $\begin{array}{l}\text { (Cervero and } \\
\text { Murakami, 2010) }\end{array}$ \\
\hline $\mathrm{D}_{\mathrm{g}}$ & QoL & Higher $\mathrm{D}_{\mathrm{g}}$ will lower the QoL. & This study \\
\hline $\begin{array}{l}\text { Natural log of } \\
\text { TCE/cap/year }\end{array}$ & QoL & $\begin{array}{l}\text { Higher TCE/Cap/year will lower the } \\
\text { QoL. }\end{array}$ & $\begin{array}{l}\text { (Delmelle et al., } \\
\text { 2013; Schneider, } \\
\text { 2013) }\end{array}$ \\
\hline $\begin{array}{l}\text { Ratio of auto } \\
\text { commuters to urban } \\
\text { population }\end{array}$ & QoL & $\begin{array}{l}\text { Higher usage of private vehicles can } \\
\text { contribute to a higher QoL; but the } \\
\text { adverse impacts of vehicles (e.g., air } \\
\text { pollution, congestions, longer trips and } \\
\text { stresses of driving) can reduce the QoL. } \\
\text { The impact of vehicle usage on the } \\
\text { QoL may not be significant. }\end{array}$ & (Mullen, 2015) \\
\hline $\begin{array}{l}\text { Natural log of per } \\
\text { capita gross } \\
\text { metropolitan } \\
\text { products }\end{array}$ & QoL & $\begin{array}{l}\text { Higher per capita gross metropolitan } \\
\text { products will promote the QoL. }\end{array}$ & $\begin{array}{l}\text { (Easterlin, 1995; } \\
\text { Easterlin and } \\
\text { Angelescu, 2012) }\end{array}$ \\
\hline
\end{tabular}

254 4. Results

255 4.1. Fractal Property of Road Networks

256 The power relationship between the number of boxes and the box size indicates scale invariance

257 (or fractal property) of the road network(Brown et al., 2002). Power plots for metropolitan Atlanta are

258 shown as an example in Fig. 3. We found that the road networks of the largest 95 U.S. metro areas are

259 fractals in terms of both geometrical topology and structuralhierarchy. 


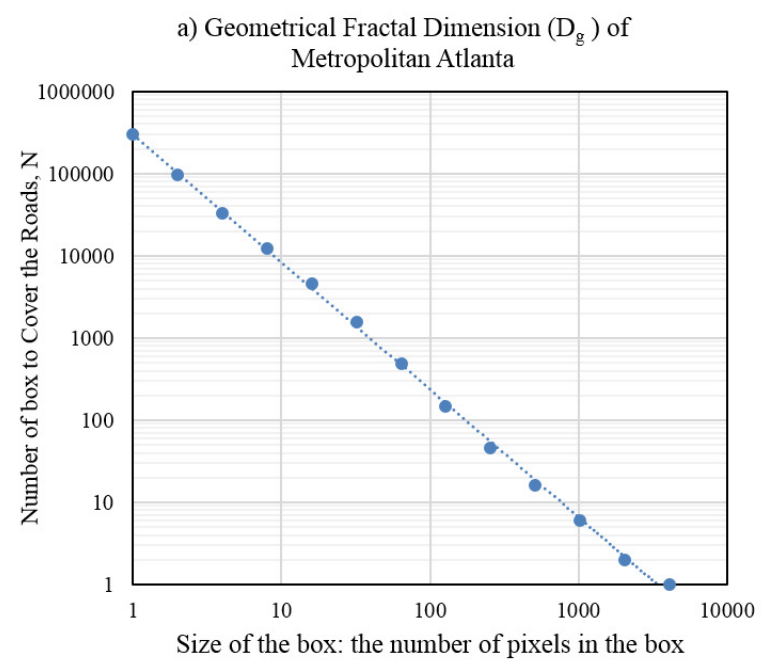

260 structural road networks.a) $\mathrm{D}_{\mathrm{g}}=1.61$; and b) $\mathrm{D}_{\mathrm{s}}=3.36$.

\subsubsection{Geometrical Fractal Dimension $\left(D_{g}\right)$} represents a more uniformly distributed network. b) Structural Fractal Dimension $\left(D_{\mathrm{s}}\right)$ of

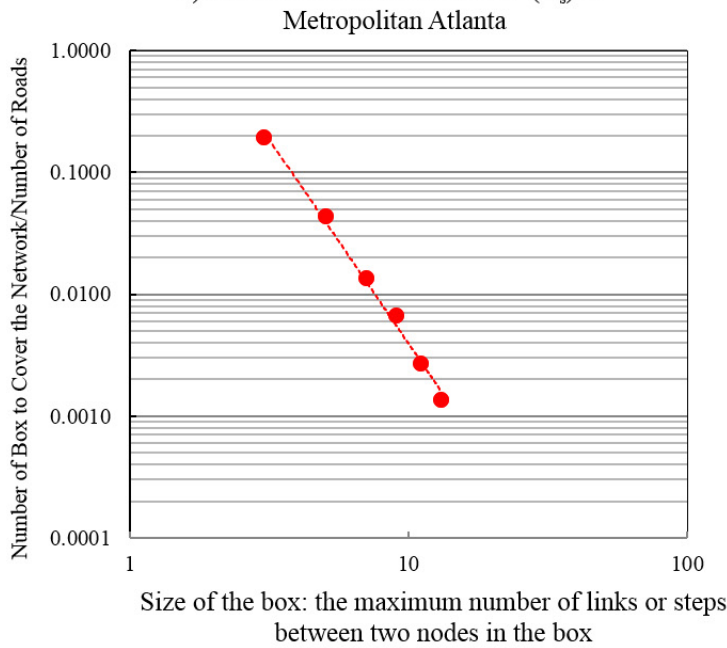

Fig. 3. The power plot of the road network in metropolitan Atlanta: the power relationship between the number of boxes and the box size shows scale invariance (or fractal property) of the geometrical and

The $\mathrm{D}_{\mathrm{g}}$ valuesobtained forour 95 metro area road networks were found to range in values from 1.2 to 1.7 (See Appendix A.Table A.1). The Boston-Cambridge-Newton, MA-NH Metro area shows the largest $\mathrm{D}_{\mathrm{g}}(1.68)$ and the Boise City-Nampa, ID Metro area shows the smallest $\mathrm{D}_{\mathrm{g}}(1.26)$. As shown in Fig. 4, we found that the smaller the $\mathrm{D}_{\mathrm{g}}$, the more dramatically the density of road network decreases from the center of the urban area to suburban and more rural areas. Conversely, as $\mathrm{D}_{\mathrm{g}}$ increases the density of the road network in suburban areas is getting closer to that in more central urban areas. That is, a larger $D_{g}$ 


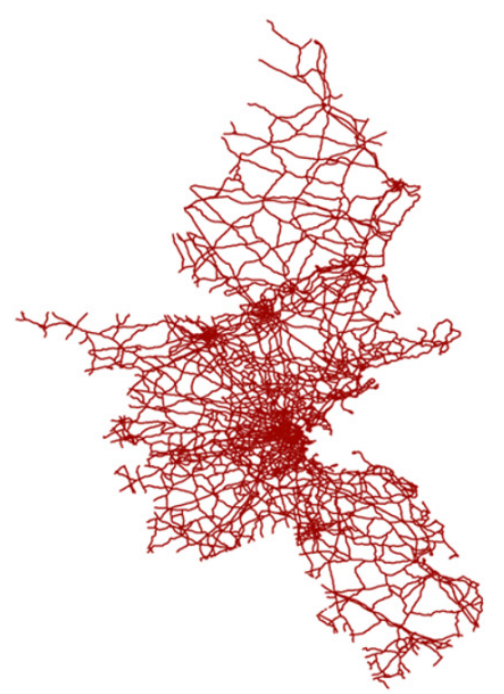

Boston-Cambridge-Quincy, MA-NH

$(\mathrm{Dg}=1.68)$

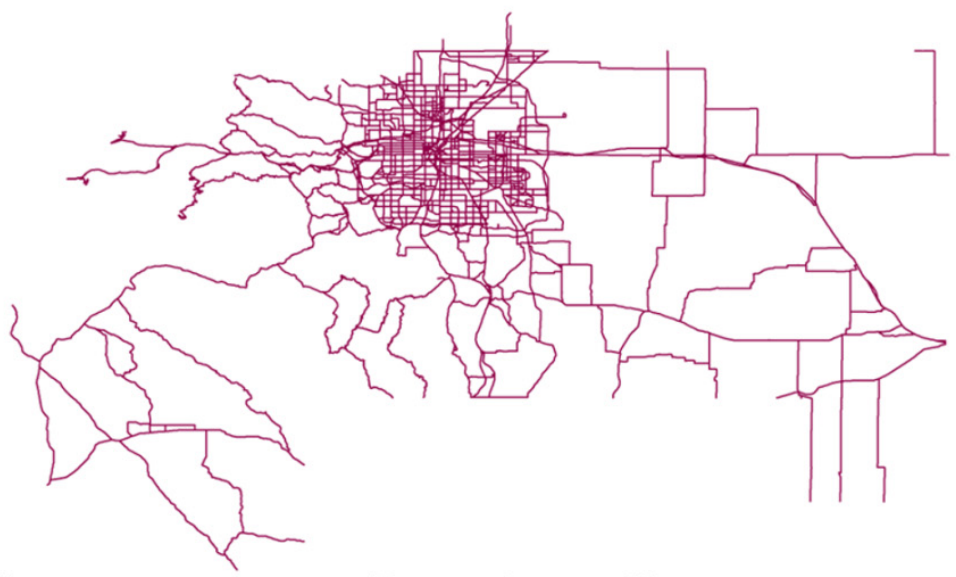

Denver-Aurora, $\mathrm{CO}$

$(\mathrm{Dg}=1.45)$

Fig.4. $\mathrm{D}_{\mathrm{g}}$ and corresponding road networks: a road network with large $\mathrm{D}_{\mathrm{g}}$ fills up the entire metropolitan

274 area.

\section{$275 \quad$ 4.1.2. Structural Fractal Dimension $\left(\mathbf{D}_{\mathbf{s}}\right)$}

The $D_{s}$ values for the road networks of the 95 metro areas analyzed range from 2.2 to 3.6 (See

277 Appendix A. Table A.1). The Milwaukee-Waukesha-West Allis, WI Metro area has the road network with

278 the largest $\mathrm{D}_{\mathrm{s}}(3.64)$ and the Salt Lake City, UT Metro area has the road network with the smallest $\mathrm{D}_{\mathrm{s}}(2.08)$.

279

We calculated the ratio of CCs between the original and rewired road structural networks to quantify the loss of small-world effects and found the positive correlation between loss of small-world

281 effect and $D_{\mathrm{s}}$ (See Fig.5). The average betweenness of the roads decreases as $\mathrm{D}_{\mathrm{s}}$ increases (see Fig. 6).

282 Therefore, combing the theoretical growth mechanism of small-world and fractal network with the

283 empirical findings in real road structural networks, we concluded that the larger value of $D_{\mathrm{s}}$ is associated

284 with more significant small-world effect.The value of $D_{s}$ can help distinguish the difference of how roads

285 are connected with each other. 


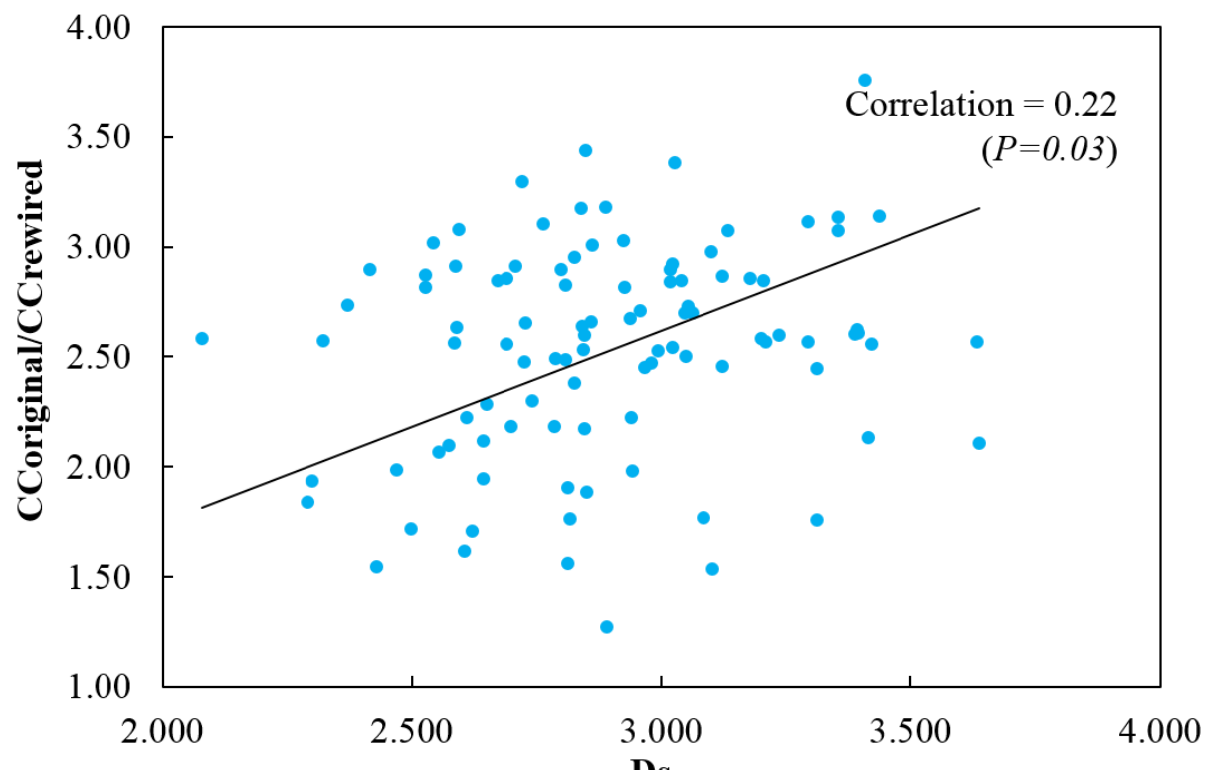

289 Fig. 5. Statistically significant correlation between the loss of small-world effect due to random rewiring 290 and $\mathrm{D}_{\mathrm{s}}$ of road structural networks: $\mathrm{CC}$ is clustering coefficient (see Eqs. 1 and 2).

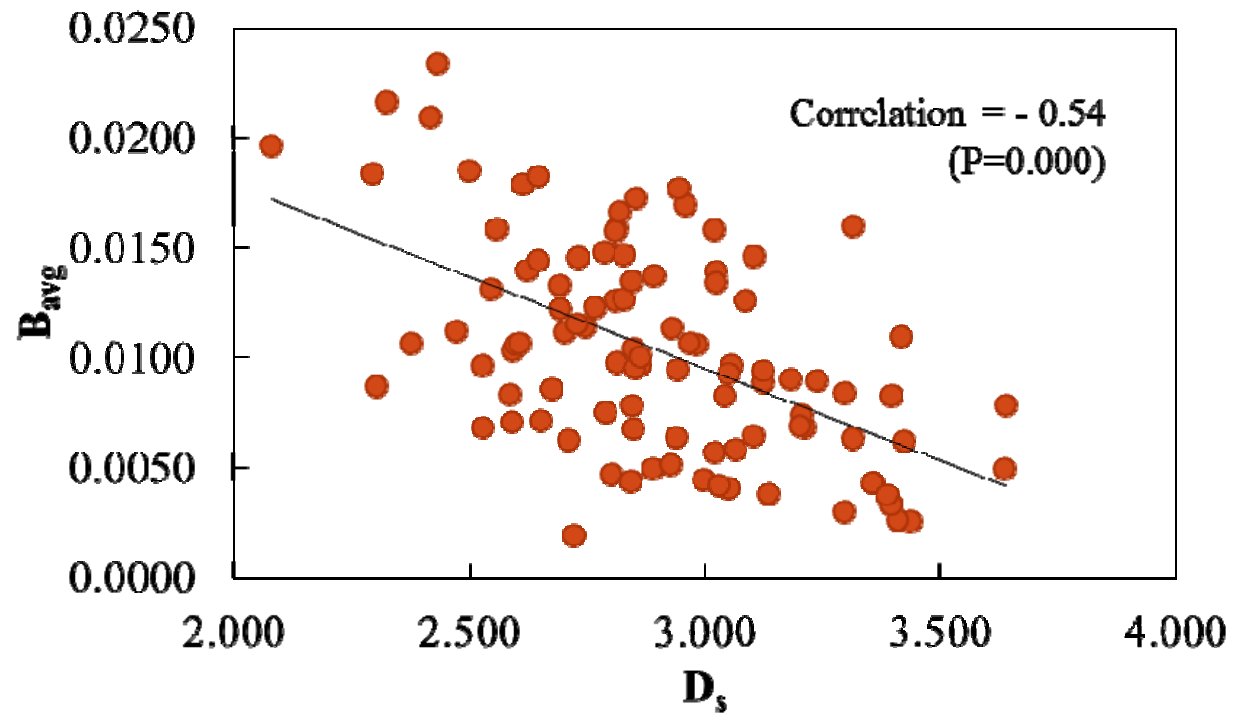

292 Fig. 6.Statistically significant correlation between $B_{\text {avg }}$ and $D_{s}$ of road structural networks: $B$ is average betweenness of nodes in the network.

\section{4.2. Summary of Path Analysis}

\subsubsection{Effectson UPD}



UPD (path coefficient $\mathrm{B}=-4.35$ ). The negative impact of $\mathrm{D}_{\mathrm{g}}$ on UPDis mitigated by the population given a positive interaction effect between $\mathrm{D}_{\mathrm{g}}$ and population in UPD $(\mathrm{B}=0.19)$. Results of path analysis also show other factors that influence the UPD. Density of urban roadway lane miles also has a significant and positive association with UPD $(\mathrm{B}=0.59)$. High density of lane miles can be understood as an incentive to high-density development by providing as many people as possible the accessibility to products, services and business. The path model explained $73 \%$ of the variance in UPD, indicated by the $\mathrm{R}^{2}$ value $(0.73)$.

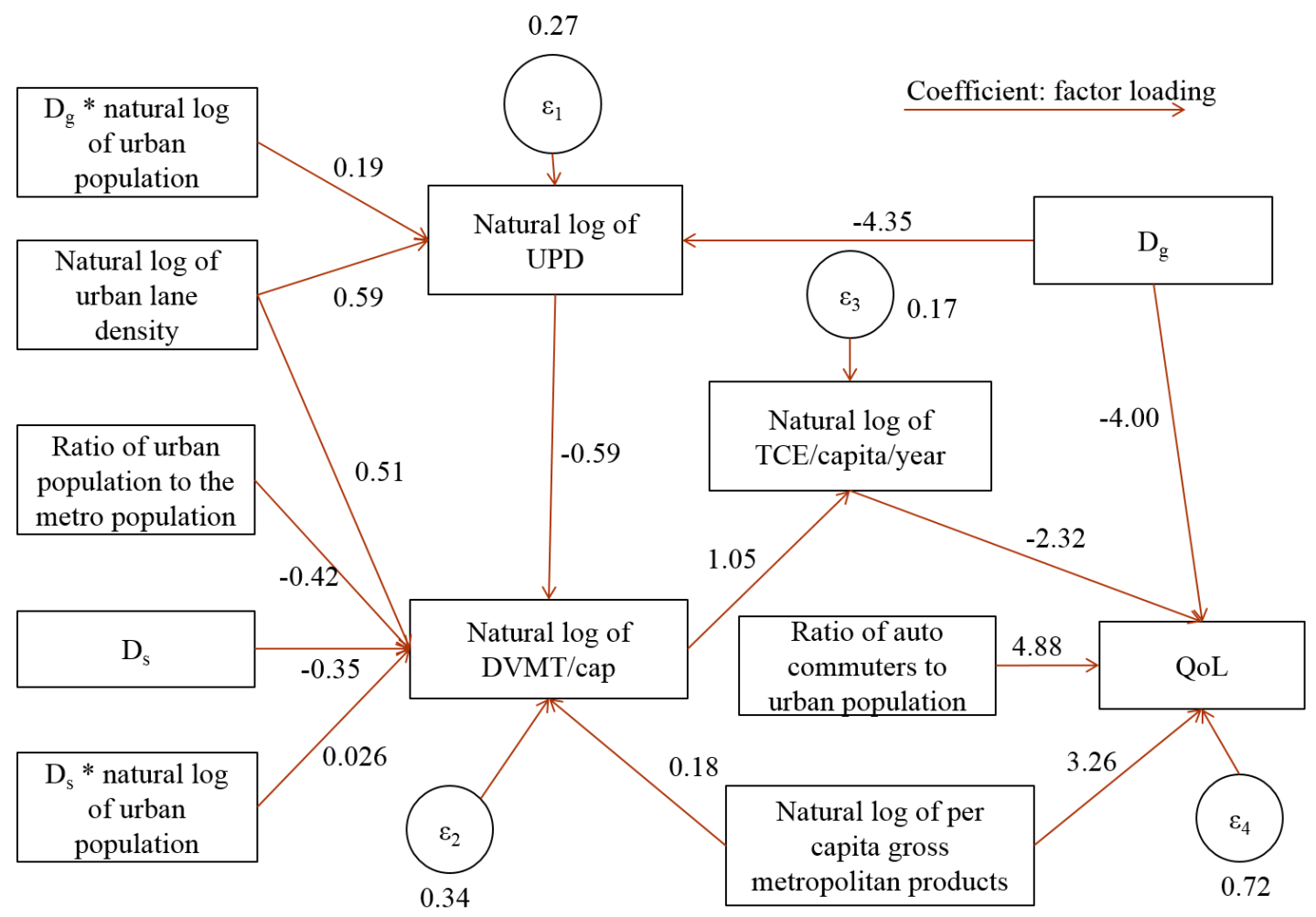

Fig. 7. Results of path analysis: all the path coefficients are significant $(\mathrm{p}<0.05)$ except the link from Ratio

303 of auto commuters to urban population to QoL. Summary of statistics is available in the AppendixA (See 304 TablesA.2-5).

\subsubsection{Effects on DVMT/Cap}

The direct negative effect of $D_{s}$ on DVMT/Cap is revealed by the path shown in Fig. 7.A larger $D_{s}$ is associated with fewer DVMT/Cap $(B=-0.35)$. However, this significant negative direct effect is offset somewhat by the interaction between $\mathrm{D}_{\mathrm{s}}$ and urban population $(\mathrm{B}=0.026)$, yielding a net positive effect of 
$\mathrm{D}_{\mathrm{s}}$ on DVMT/Cap for urban populations larger than $700,000\left(-0.35 \mathrm{D}_{\mathrm{s}}+0.026 \mathrm{D}_{\mathrm{s}} * \ln\right.$ (urban population) $=0$, in which urban population $=701,894$ ). We also find a negative influence of UPD on DVMT/Cap.A 100\% increase in UPD is associated with 59\% decline in DVMT/Cap (B = -0.59). Higher UPD provides incentives for compact development and public transportation, which could reduce vehicle miles traveled. High density of roadway lanes is associated with large DVMT/Cap $(B=0.51)$. The increase in road supply

314 can stimulate the travel demand. People tend to drive longer in a metro area withhigher per capita gross 315 metropolitan products $(\mathrm{B}=0.18)$. Commuting to workplaces and driving to fulfill personal needs is 316 positively correlated with economic growth (Ecola and Wachs, 2012).A higher ratio of peopleliving in 317 urban areas to total population of the entire metro area is associated with reduced DVMT/Cap $(B=-$ 318 0.42).Households living in rural areas tends to have higher DVMT/Cap(U.S Department of Transportation, 319 2009). The pathmodel explained $64 \%$ of the variance in the DVMT/Cap, indicated by the $\mathrm{R}^{2}$ value $(0.64)$.

\section{$320 \quad$ 4.2.3. Effects onTCE/Cap/year}

We find that DVMT/Cap directly affectsthe TCE/Cap/year. Specifically, a1\% increase in

322 DVMT/Cap is associated with a 1.05\% increase in TCE/Cap/year $(\mathrm{B}=1.05)$. The path model explained $83 \%$

323 of the variance in TCE/Cap, indicated by the $\mathrm{R}^{2}$ value $(0.83)$.

324 According to the paths show in Fig. 7, $\mathrm{D}_{\mathrm{g}}$ affects TCE/Cap/yearindirectly through the impacts on

325 UPD and DVMT/Cap. An increase in $\mathrm{D}_{\mathrm{g}}$ will lead to a decline in UPD and further an increase in

326 DVMT/Cap. As a result, the TCE/Cap/yearwill increase. Population size of a metro area can mitigate the

327 negative impact of $\mathrm{D}_{\mathrm{g}}$ on TCE/Cap/year. $\mathrm{D}_{\mathrm{s}}$ indirectly affects TCE/Cap/yearthrough the impacts on

328 DVMT/Cap. Population size determines the negative or positive impacts of $\mathrm{D}_{\mathrm{s}}$ on TCE/Cap/year. When

329 population size is small, the effect of $\mathrm{D}_{\mathrm{s}}$ alone is dominant. An increase in $\mathrm{D}_{\mathrm{s}}$ will lead to a decrease in

330 DVMT/Cap and consequently a decrease in TCE/Cap/year. However, when population size is large, the

331 interactive effect of $D_{s}$ and urban population overwhelms that of $D_{s}$ alone. An increase in $D_{s}$ willlead to an

332 increase in DVMT/Cap and an increase in TCE/Cap/year. We plot $\mathrm{D}_{\mathrm{s}}$ versus TCE/Cap/year for metro areas

333 with more than 5,000,000 populations. As shown in Fig. 8, the $\mathrm{D}_{\mathrm{s}}$ and TCE/Cap/yearof metro areas with 334 more than $5,000,000$ populations is positively correlated. 


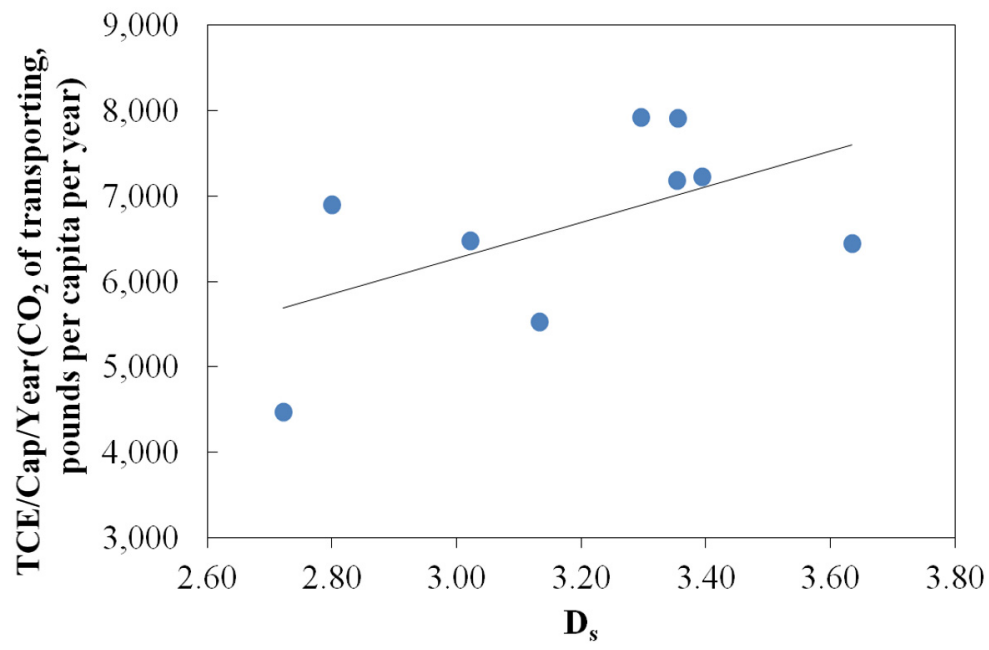

336 Fig.8. The impact of $D_{s}$ on TCE/Cap/year based on metro areas with more than 5,000,000 populations.

\subsubsection{Effects on QoL}

The $\mathrm{D}_{\mathrm{g}}$ is found to have a strong direct negative effecton $\mathrm{QoL}(\mathrm{B}=-4.0)$. Metro areas with larger TCE/Cap/yeartend to have lowerQoLbecauselarger TCE/Cap/yearis associated with longer driving distances and more congestion ( $\mathrm{B}=-2.32$ ). Given the negative effect of $\mathrm{D}_{\mathrm{g}}$ on TCE/Cap/year, an increase in $\mathrm{D}_{\mathrm{g}}$ can indirectly lower QoL. Similarly, $\mathrm{D}_{\mathrm{s}}$ has an indirect impact on TCE/Cap/year, and correspondingly affect the QoL. When population size is small, a larger $\mathrm{D}_{\mathrm{s}}$ can lead to an increase in QoL. However, when population size grows bigger, a larger $\mathrm{D}_{\mathrm{s}}$ can lead to a decline in QoL.Higherper capita gross metropolitan productsis, as expected, associated with higher QoL $(\mathrm{B}=3.26)$.However, the use of automobiles (i.e. the ratio of auto commuters to total urban population) does not significantly affect $\mathrm{QoL}(\mathrm{B}=4.87, \mathrm{P}=0.24)$. It indicates the necessity of planning for multiple transport modes to ensure both personal ride comfort and the city-wide urban traffic environment. The path modelexplained $29 \%$ of the variance in QoL, as indicated by the $\mathrm{R}^{2}$ value (0.29).

\section{Discussion}

In general, the results of path analysis validated our hypotheses of the positive and negative impacts of $\mathrm{D}_{\mathrm{g}}$ and $\mathrm{D}_{\mathrm{s}}$ on UPD, DVMT/Cap, TCE/Cap/year and QoL.But the applicability of $\mathrm{D}_{\mathrm{g}}$ and $\mathrm{D}_{\mathrm{s}}$ is not limited to the explanations of these four variables. For example, the explanation of how $D_{s}$ affect DVMT/cap could also be applied to understand the traffic congestion. The wasted carbon emission per capita (WCE/Cap) due to congestion was found to be negatively associated with $\mathrm{D}_{\mathrm{s}}$ (See Appendix A.Table 
A.6). However, we also find that population growth has offset to some extent the beneficial effect of a high

$\mathrm{D}_{\mathrm{s}}$ value on reduced congestion.Due to the dominance of freeways and the cluster of destinations (e.g.,

357 workplaces, commercial centers) around freeway intersections, in case of large $\mathrm{D}_{\mathrm{s}}$, population

358 growthsubstantially increases the chances of freeway congestion.For road networks with small $\mathrm{D}_{\mathrm{s}}$ values,

359 freeways are found to be indirectly connected through arterials and collectors, which createa buffer

360 between freeways. The travel destinations are dispersed along the road network. Both can reduce the

361 likelihood of traffic congestion.Overall, it might provide an opportunity to use fractal dimensions for

362 developing planning strategies for more sustainable transportation and land use.

Although we found some direct paths from $\mathrm{D}_{\mathrm{g}}$ and $\mathrm{D}_{\mathrm{s}}$ to the urban built environment, westill did not verify the process of how $\mathrm{D}_{\mathrm{g}}$ and $\mathrm{D}_{\mathrm{s}}$ affect the land use and transportation as described in the hypophyses in Section 2. In the future study, we will define variables that can characterize the local

366 dependences or the space filling capability based on land constraints, policies and economic development 367 and test the correlationwith $\mathrm{D}_{\mathrm{g}}$. Also, we will have metrics that characterize the mixed land use pattern and 368 test the correlation with $\mathrm{D}_{\mathrm{s}}$. In terms of measures of the emergent land use pattern, we only compared the 369 UPD as one general property among cities. However, we did not measure the impacts of $\mathrm{D}_{\mathrm{g}}$ and $\mathrm{D}_{\mathrm{s}}$ on 370 spatial difference in density across the city like the research in 2002(Shen, 2002). The impacts of $D_{g}$ and $D_{s}$ 371 on other measures of urban structure such as job-housing balance should be investigated in the future. By

372 adding the aforementioned variables and metrics to our current path model, we might be able to connect

373 policy toolsand planning strategies with $\mathrm{D}_{\mathrm{g}}, \mathrm{D}_{\mathrm{s}}$ as well as theemergent pattern of land use and 374 transportation.

375 We started this fractal analysis in 2013 by looking at road networks in 2005 and the impacts on the 376 urban built environment in 2011. Since 2012, urban mobility reports are available for the DVMT/Cap and 377 TCE/Cap/year. At the same time, more updated road networks, such as TIGER files, are available to trace 378 the changes in $D_{g}$ and $D_{s}$ after 2005.In the future, we will use these panel data to further explore the 379 adaptive evolution of the fractal dimensions of road networks and the urbanbuilt environment.

\section{6. Conclusion}

In summary, we have shown that the fractal dimension $\mathrm{D}_{\mathrm{g}}$ and $\mathrm{D}_{\mathrm{s}}$ can offer comprehensive metrics that may afford planners a better understanding of urban system spatial dynamics.Metropolitan area road 
networks with a large $D_{g}$ tend to be more evenly spread over their entire geographic region, while road networks with a small $D_{g}$ are likely to have decreasing road density when moving from the center to the border of the metro area. The magnitude of $\mathrm{D}_{\mathrm{s}}$ was found to reflect a trade-off between small-world and fractal properties of the road structural network. A large $D_{\mathrm{s}}$ means that the metro area's road network demonstrates a significant small-world property. A small $\mathrm{D}_{\mathrm{s}}$ means that the road network has a more distinct fractal hierarchy but at the expense of its small-world property. Using path analysis, we further explored and explained the connections of $\mathrm{D}_{\mathrm{g}}$ and $\mathrm{D}_{\mathrm{s}}$ with the urban built environment. An increase in $\mathrm{D}_{\mathrm{g}}$ directly leads to a lower UPD and QoL. An increase in $\mathrm{D}_{\mathrm{s}}$ contributes to a decrease in DVMT/Cap when the urban population is small, but when population is large, an increase in $\mathrm{D}_{\mathrm{s}}$ can lead to the increase in DVMT/Cap.More investigations of these connections will be needed in the future studies to prove the usefulness of $\mathrm{D}_{\mathrm{g}}$ and $\mathrm{D}_{\mathrm{s}}$ in planning and design road network infrastructures to create a more sustainable urban environment.

\section{References}

Abundo, C., Bodnar, T., Driscoll, J., Hatton, I., Wright, J., 2013. City population dynamics and fractal transport networks, 2013 Complex Systems Summer School Proceedings.

Batty, M., Longley, P.A., 1994. Fractal cities: a geometry of form and function.

Batty, M., Xie, Y., 1996. Preliminary evidence for a theory of the fractal city. Environment and Planning A 28, 1745-1762.

Bentler, P.M., Chou, C.P., 1987. Practical issues in structural modeling. Sociological Methods \& Research 16, 78-117.

Brown, J.H., Gupta, V.K., Li, B.-L., Milne, B.T., Restrepo, C., West, G.B., 2002. The fractal nature of nature: power laws, ecological complexity and biodiversity. Philosophical Transactions of the Royal Society of London B: Biological Sciences 357, 619-626.

Cervero, R., 2003. Road expansion, urban growth, and induced travel - a path analysis. Journal of the American Planning Association 69, 145-163.

Cervero, R., Murakami, J., 2010. Effects of built environments on vehicle miles traveled: evidence from 370 US urbanized areas. Environment and Planning A 42, 400-418.

Chen, Y., 2012. Fractal dimension evolution and spatial replacement dynamics of urban growth. Chaos, Solitons \& Fractals 45, 115-124.

Delmelle, E.C., Haslauer, E., Prinz, T., 2013. Social satisfaction, commuting and neighborhoods. Journal of Transport Geography 30, 110-116.

Easterlin, R.A., 1995. Will raising the incomes of all increase the happiness of all? Journal of Economic Behavior \& Organization 27, 35-47.

Easterlin, R.A., Angelescu, L., 2012. Modern economic growth and quality of life: cross-Sectional and time series evidence. Springer.

Ecola, L., Wachs, M., 2012. Exploring the relationship between travel demand and economic growth. Etminani-Ghasrodashti, R., Ardeshiri, M., 2015. Modeling travel behavior by the structural relationships between lifestyle, built environment and non-working trips. Transportation Research Part a-Policy and Practice 78, 506-518.

Ewing, R., Hamidi, S., Gallivan, F., Nelson, A.C., Grace, J.B., 2014. Structural equation models of VMT growth in US urbanised areas. Urban Studies 51, 3079-3096.

Gallup, Healthways, 2013. State of American well-being, 2013 state, community, and congressional district analysis. 
Hu, L.T., Bentler, P.M., 1999. Cutoff criteria for fit indexes in covariance structure analysis: conventional criteria versus new alternatives. Structural Equation Modeling-a Multidisciplinary Journal 6, 1-55. Kalapala, V., Sanwalani, V., Clauset, A., Moore, C., 2006. Scale invariance in road networks. Physical Review E 73.

Kitsak, M., Havlin, S., Paul, G., Riccaboni, M., Pammolli, F., Stanley, H.E., 2007. Betweenness centrality of fractal and nonfractal scale-free model networks and tests on real networks. Physical Review E 75. Latora, V., Marchiori, M., 2001. Efficient behavior of small-world networks. Physical Review Letters 87. Lin, J.J., Yang, A.T., 2009. Structural analysis of how urban form impacts travel demand: evidence from Taipei. Urban Studies 46, 1951-1967.

Lu, Y.M., Tang, J.M., 2004. Fractal dimension of a transportation network and its relationship with urban growth: A study of the Dallas-Fort Worth area. Environment and Planning B-Planning \& Design 31, 895911.

Mandelbrot, B.B., 1983. The fractal geometry of nature. Macmillan.

Meakin, P., 1983. Formation of fractal clusters and networks by irreversible diffusion-limited aggregation. Physical Review Letters 51, 1119-1122.

Moisy, F., 2008. Computing a fractal dimension with Matlab: 1D, 2D and 3D box-counting.

Mullen, C., 2015. Book review: The Car Dependent Society: A European Perspective. Urban Studies, 0042098015586695.

Nasri, A., Zhang, L., 2014. Assessing the impact of metropolitan-level, county-level, and local-level built environment on travel behavior: evidence from 19 US urban areas. Journal of Urban Planning and Development.

Niemeyer, L., Pietronero, L., Wiesmann, H.J., 1984. Fractal dimension of dielectric-breakdown. Physical Review Letters 52, 1033-1036.

Schneider, I.E., 2013. Quality of life: assessment for transportation performance measures.

Schrank, D., Eisele, B., Lomax, T., 2012. TTI's 2012 urban mobility report. Texas A\&M Transportation Institute; The Texas A\&M University System.

Shen, G.Q., 2002. Fractal dimension and fractal growth of urbanized areas. International Journal of Geographical Information Science 16, 419-437.

Silva, J.D.E., Morency, C., Goulias, K.G., 2012. Using structural equations modeling to unravel the influence of land use patterns on travel behavior of workers in Montreal. Transportation Research Part aPolicy and Practice 46, 1252-1264.

Song, C.M., Havlin, S., Makse, H.A., 2006. Origins of fractality in the growth of complex networks. Nature Physics 2, 275-281.

Thomas, I., Frankhauser, P., 2013. Fractal dimensions of the built-up footprint: buildings versus roads. Fractal evidence from Antwerp (Belgium). Environment and Planning B-Planning \& Design 40, 310-329. U.S Department of Transportation, F.H.A., 2009. 2009 National Household Travel Survey.

Wade, T.G., Wickham, J.D., Bradford, D.F., 1999. Accuracy of road density estimates derived from USGS DLG data for use in environmental applications. Photogrammetric engineering and remote sensing 65, 1419-1426.

Zhang, H., Li, Z.L., 2012. Fractality and self-similarity in the structure of road networks. Ann. Assoc. Am. Geogr. 102, 350-365. 